\title{
Access Prices Indexed to Geographical Coverage of Innovative Telecom Services
}

\section{David Henriques ${ }^{1,2}$}

Received: 23 December 2019 / Revised: 29 April 2020 / Accepted: 4 August 2020 /

Published online: 27 August 2020

(C) The Author(s) 2020

\begin{abstract}
The literature on access prices and investment has suggested that firms under-invest when subject to an access provision obligation combined with a fixed access price per consumer. In this paper, I study an access price per consumer for an innovative service such as superfast broadband provided by a regulated firm that is a function of its geographical coverage (indexation approach). The indexation approach can enhance economic efficiency beyond what is achieved with a fixed access price under a set of standard assumptions. In particular, it can simultaneously induce the firms to set lower retail prices, lead to wider geographical coverage of innovative services and higher social welfare level compared with a fixed access price. Moreover, in the model, the indexation may be used to achieve approximately the Ramsey outcome, or the first-best coverage level. I address how a regulator can set the access price indexation optimally, based on the coverage cost plus an incentive. I highlight the potential role of indexation as a tool to reduce the need for public subsidies and the associated tax distortions when compared with a fixed access price.
\end{abstract}

Keywords Geographic coverage · Innovation · Investment incentives · Price controls

JEL Classification L43 · L51 · L96

\section{Introduction}

Motivation A key concern for Europe and the USA is the timely rollout of innovative high-speed broadband services. The European Commission (2016) has set a target for all European homes to have access to a download speed of at least $100 \mathrm{Mbps}$ by 2025 , while the Federal Communications Commission (2016) has set a goal for all US Americans to have access to affordable, high-quality broadband. These high-speed services have the potential to offer considerable benefits to businesses to remain or become more competitive, allow

David Henriques

dthenriques@gmail.com

1 London School of Economics and Political Science London, London, UK

2 RBB Economics, London, UK 
consumers to benefit from advanced online services that improve their quality of life, and induce significant growth across major economic sectors (Czernich et al. 2011).

Fibre optics is one of the fastest technologies for content transmission (both downloading and uploading), allowing for significantly faster and wider transmission of information than current copper-based networks. However, the private sector has been reluctant to invest in a large-scale deployment of Next Generation Access Networks (NGA), namely fiber-based networks. ${ }^{1}$ Insofar as the fiber rollout cost increases substantially when population density falls, this has led to concerns on the ability of firms to extend geographical coverage outside major urban areas. One reason for under-investment in NGA coverage relates to the inability of firms to capture the full social benefit from that investment. Another potential reason for under-investment is the lack of access to finance.

In the introduction phase of innovative services requiring significant investment in geographical coverage such as high-speed broadband, regulators are likely to face a trade-off between static (price) and dynamic (coverage) efficiency. I question how such a trade-off can be softened. I investigate the impact of different access price controls on the firms' choices of geographical coverage of innovative services, and on downstream prices. The aim of this paper is to seek access price control rules that encourage further coverage without increasing downstream prices relative to a standard fixed price control approach.

Related Literature This paper draws from the strand of literature on the interplay between access price regulation and private investment, especially on geographical deployment of new networks. Faulhaber and Hogendorn (2000) and Foros and Kind (2003) and Valletti et al. (2002) are important contributions to the research on geographical deployment of broadband networks. These articles studied the effects of universal service and uniform retail pricing obligations on coverage. However, they did not address the impact of access price regulation.

Hori and Mizuno (2009) compared service-based and facility-based competition in terms of a firm's incentive to invest in network infrastructure under uncertainty. Brito et al. (2010) showed that two-part access tariffs might enable a regulator to incentivize an operator to invest on NGA. However, neither of the two addresses investment in geographical coverage.

Lestage and Flacher (2009) pioneered the research of the impact of access regulation on geographical coverage within the context of competition for rolling out new telecommunications infrastructures. They proposed a model for the decision about "if" and "where" to deploy a new infrastructure, and showed that access regulation reduces the area of facilitybased competition and extends the area where no firm is willing to invest. However, they did not consider access price rules as a function of investment levels. ${ }^{2}$

Only exceptions such as Hurkens and Jeon (2008), Klumpp and Su (2010), Nitsche and Wiethaus L (2011), and Henriques (2011) and Sauer (2012) have considered the idea of access prices as a function of strategic variables, e.g., retail prices, quantities, or geographical coverage, as a means to improve welfare outcomes. Henriques (2011) and Sauer (2012) are the closest research works to this paper studying access prices for NGA as linear functions of geographical coverage. Both papers showed that such access prices incentivize further coverage from firms when compared with a fixed access price. However, these

\footnotetext{
${ }^{1}$ Aside from fiber, there are a number of alternative technologies capable of supporting NGA. Since fiber is one of the fastest technologies for content transmission, debates on wired NGA have focused on fiber deployment. I will use "NGA" and "fiber-based networks" interchangeably.

${ }^{2}$ See Valletti (2003) and Guthrie (2006) and Cambini and Jiang (2009) for excellent reviews on how access pricing and network investments have been investigated by the theoretical literature. This literature points to the need to consider more deeply the impact of access regulation on investments and on welfare.
} 
papers rely on specific assumptions, e.g., Hotelling model and quadratic cost of coverage. They do not show whether the Ramsey outcome or the first-best coverage level could be achieved under more general sets of assumptions.

Other forms of access price, e.g., dependent on how much entrants invest, or the timing of investment, were studied by Cave and Vogelsang (2003) and Cave (2006) with the concept of "ladder of investment," Gans (2001), and Hoernig and Vareda (2010). More recent papers that studied the impact of access regulation on investment are the following. Flacher and Jennequin (2014) compared different regulatory regimes in terms of geographic coverage and welfare levels. They showed that coverage and number of users as well as social welfare will be highest with direct regulation of both infrastructure deployment and access price. Bourreau et al. (2015) proposed access regulations tailored to each geographical area depending on the degree of infrastructure competition. They showed that geographically differentiated access prices can enhance welfare and promote investment compared with a uniform access price.

Description of the Paper I compare the outcomes of a standard model obtained under a fixed access price and an access price as a function of NGA coverage (indexation, for short) in terms of retail prices, NGA coverage, and social welfare levels. The indexation approach corresponds to a regulator setting out a menu of options in which the regulated firm faces a choice of access price-coverage regulatory contracts. In theory, a regulator could set directly the price and investment in coverage that maximizes social welfare. However, in practice, regulators may not have the powers to set such investment levels for a firm, and firms face financial constraints which may be difficult to observe and verify by a regulator. Setting out a menu of options for the regulated firms to choose from, rather than imposing price and coverage levels directly, can avoid regulatory risks, e.g., forcing the firm to make an investment that it cannot afford, as well as incentivize the firm to invest up to the maximum amount that it can achieve.

A distinctive feature of the access price indexation is to reward a regulated firm depending on the NGA coverage achieved. The firm is rewarded for covering a marginal area with NGA by increasing the access price in all (i.e., marginal and inframarginal) covered areas. Thus, the indexation grants an increasing competitive advantage at the downstream level as the regulated firm covers further areas. A key factor influencing firms' incentives to invest and provide NGA services in an area is the incremental net revenues they can earn over and above providing their existing copper-based services in that area. Mechanisms which increase the incremental net revenues from NGA deployment can therefore have a positive effect on NGA coverage. Under a fixed access price and assuming copper-based services provided in a competitive basis at zero economic profit, the incremental net revenue of covering an additional area with NGA is the profit from that area only. However, under the indexation approach, the incremental net revenue of covering an additional area with NGA is the profit from that area plus the incremental profit from all inframarginal areas already covered with NGA. Thus, to achieve the same level of geographical coverage, the firm will require a lower access price under indexation than with a fixed access price.

This paper extends both Henriques (2011) and Sauer (2012) by considering a more general set of properties for welfare, revenue, and cost of coverage, as well as non-linear access prices. The main contribution of this paper is to show that, under a standard set of assumptions, setting an access price as a function of NGA coverage can improve economic efficiency beyond what is feasible with a fixed access price. The indexation dominates a fixed access pricing rule in terms of retail price efficiency (i.e., the number of consumers served with a fiber connection), investment efficiency (i.e., total NGA coverage), and social welfare. Moreover, I address how a regulator can set the access price indexation optimally 
(based on the coverage cost plus an incentive), rather than assuming linearity as in Henriques (2011) and Sauer (2012). I show that the access price indexation can be used to achieve approximately the Ramsey outcome, or the first-best coverage level. I abstract from other potential policies designed to promote coverage (e.g., subsidies) treating them as independent of price controls.

The rest of the paper is organized as follows. Section 2 sets up a service-based competition model. Section 3 defines the first- and the second-best, as well as the free market (monopoly) solution as benchmarks. Section 4 sets out the analysis under a standard fixed access price approach. Section 5 repeats the analysis with the access price indexation and compares it against the fixed access price approach and benchmarks previously considered. Section 6 discusses further features of access price indexation and the robustness of the results. Section 7 concludes the paper. Proofs can be found in the Appendix.

\section{Service-Based Competition Model}

In this section, I set out a service-based competition model with an incumbent firm and a competitive fringe. I use this model to study the impact of different access price control rules on retail prices, NGA geographical coverage, and welfare. I assume that consumers do not differentiate between fiber services provided by different firms. Table 1 below summarizes the timing of the game. This structure is natural as firms decide on retail prices in the short run and on investments in the long run, while regulators decide on the access price strategy in the very long run. Further below I describe each of the participants in the model: firms, sectoral regulator, and consumers.

Firms There is a profit maximizing incumbent firm and a competitive fringe which seeks access to the incumbent's NGA. A superfast broadband service can be offered in areas where NGA infrastructure has been rolled out. The competitive fringe cannot bypass the incumbent's NGA to provide superfast broadband services. The country is represented by a continuum of areas $x \in[0, \bar{K}]$ ordered by decreasing population density, but each with identical demand for superfast broadband services. The deployment total cost of the NGA is convex because it is more expensive to cover (marginal) peripheral areas with lower population density. ${ }^{3}$ I assume that the total cost of deploying NGA in $k$ areas is given by $C(k) \equiv \int_{0}^{k} c(x) d x$ with $C(0)=0, C^{\prime}(k)=c(k)>0, C^{\prime \prime}(k)=c^{\prime}(k)>0$ and $C^{\prime \prime \prime}(k)=c^{\prime \prime}(k) \geq 0$ where $c(x)$ is the NGA deployment cost in area $x$. A Current Generation Access Network (CGA), i.e., standard broadband, is assumed to be ubiquitous in the country.

Once an area $x$ is covered with NGA, the marginal cost of providing superfast broadband to a consumer is zero for the incumbent, while the accessing firms face a marginal cost equal to the access price, $a$. I assume that all firms set retail prices independently of the traffic volume exchanged in communications made by the consumer, e.g., a periodical subscription fee. This reflects the fact that currently in Europe and in the USA a number of broadband offers are flat rates.

I assume that the incumbent's revenue per area, $r(a)$, in areas where it has deployed NGA, is a function of the access price and satisfies the following standard properties: $r(0)=$

\footnotetext{
${ }^{3}$ The area $x=0$ is the smallest and has the highest population density, while the area $x=\bar{K}$ is the largest and has the lowest population density. It is widely accepted that the geographical coverage cost increases for decreasing population densities. The convexity of costs also applies to postal services and some mobile telephone systems. See Foros and Kind (2003).
} 
Table 1 Timing of the service-based competition model with a homogeneous service

I

II.

III.
The sectoral regulator defines the access price control rules per consumer, $a$, for an innovative service provided by an incumbent firm on its NGA infrastructure.

The incumbent firm chooses the areas to cover with NGA infrastructure. The accessing firms observe costlessly the NGA coverage.

Firms compete simultaneously and non-cooperatively in retail prices for superfast broadband. With homogeneous services, consumers choose the service with the lowest price. If all services are priced the same, then consumers choose the one provided by the incumbent.

$0, r^{\prime}(a)>0$ for $a \in\left[0 ; a^{m o n}\right), r^{\prime}(a)=0$ at $a=a^{m o n}>0, r^{\prime}(a)<0$ for $a>a^{m o n}$, and $r^{\prime \prime}(a)<0$, where a variable with mon in superscript refers to the monopoly equilibrium. In what follows $r^{-1}$ refers to the inverse function of $r$ restricted to $a \in\left[0 ; a^{m o n}\right)$ because access prices above the monopoly level are not relevant for the analysis. Given that firms compete in prices and there is no differentiation, the revenue per area is defined as $r(a) \equiv$ $a q(a)$, where $q(a)$ is the number of NGA consumers in an area with both access and retail price $a$. No service differentiation implies that the competitive fringe sets the retail price equal to the wholesale price, $a$.

For technical simplicity, the demand, marginal cost per consumer, access rules, and market structure are the same across areas covered with NGA. Hence, firms will choose uniform retail prices across all areas, even if they can differentiate retail prices per geographic area.

Sectoral Regulator I assume that the regulator sets an access price rule to the incumbent's NGA that is uniform across all geographic areas. ${ }^{4}$ This reflects the fact that regulators in a number of countries have implemented uniform access price controls. In areas covered with CGA only, welfare is normalized to zero. I assume that the regulator maximizes total social welfare, $W=\int_{0}^{k}[w(a)-c(x)] d x$, ${ }^{5}$ where $w(a)$ is the social welfare per area (gross of coverage cost) in areas where superfast broadband is available and has the following standard properties: $w(0)>0 ; w^{\prime}(0)=0$ (marginal cost access pricing), $w^{\prime}(a)<0$ for $a>0$, and $w^{\prime \prime}(a)<0$. These assumptions imply that welfare in the covered areas is maximized at a cost-oriented access price. Also, I assume that the regulator can credibly commit to an access price rule, i.e., will not change the access price rule after NGA deployment.

Consumers In areas covered with CGA only, consumers use the standard broadband service. In an area $x$ covered with NGA, consumers can derive consumer surplus from the consumption of superfast broadband.

\footnotetext{
${ }^{4}$ Regulators often need to set price controls for a number of complementary wholesale access services, e.g., cables, equipment accommodation, and rentals. The access price in this model should be construed as the total price for the set of those complementary wholesale access services that are necessary to provide a service to a retail customer.

${ }^{5}$ The principal duty of some sectoral regulators, e.g., Ofcom in the UK, is to further the interests of consumers. Hence, it might be argued that more weight should be given to consumer surplus. However, firms' profits should also matter to the regulator to ensure the sustainability of the industry and because part of those profits may feed into future investments that will generate further surplus to consumers.
} 


\section{Benchmarks}

In this section, I define the first- and the second-best, as well as the free market (monopoly) solution as benchmarks.

\subsection{First-Best Benchmark}

Hereafter, a variable with $F B$ in superscript refers to the model in the first-best and FOC stands for first-order conditions. All the second-order conditions (SOC) were verified. In the first-best, a benevolent regulator solves:

$$
\begin{array}{r}
\max _{a, k} W(a, k) \equiv \int_{0}^{k}[w(a)-c(x)] d x \\
F O C:\left\{\begin{array} { l } 
{ \frac { \partial W } { \partial a } = 0 } \\
{ \frac { \partial W } { \partial k } = 0 }
\end{array} \Leftrightarrow \left\{\begin{array}{l}
a^{F B}=0 \\
k^{F B}=c^{-1}\left(w\left(a^{F B}\right)\right)
\end{array} .\right.\right.
\end{array}
$$

Hence, in the first-best solution:

$$
\left\{\begin{array}{c}
a^{F B}=0 \\
k^{F B}=c^{-1}\left(w\left(a^{F B}\right)\right) \\
\Pi^{F B}=\int_{0}^{k^{F B}}\left[r\left(a^{F B}\right)-c(x)\right] d x=-C\left(k^{F B}\right) \\
W^{F B}=\int_{0}^{k^{F B}}\left[w\left(a^{F B}\right)-c(x)\right] d x
\end{array}\right.
$$

The efficient retail prices correspond to the marginal cost of serving a NGA service to a consumer, i.e., zero by assumption. It is socially optimal to supply NGA to all consumers with a non-negative valuation of NGA services, $q(0)$, in each area covered with NGA. The efficient NGA coverage is driven by the social value $w\left(a^{F B}\right)$ and coverage cost function $c(x)$ of NGA. In the absence of lump-sum transfers the first-best is not feasible. This is because in the first-best $a^{F B}=0$, the incumbent makes zero revenue, while the NGA coverage cost is strictly positive resulting in negative profit. Thus, the incumbent would prefer not to cover any area with NGA. Below, I derive the Ramsey outcome by maximizing social welfare subject to non-negative profits to ensure the incumbent's participation.

\subsection{Second-Best Benchmark: Ramsey Outcome}

The Ramsey outcome is the best feasible outcome for society as a whole in the absence of lump-sum transfers. Hereafter, a variable with $R$ in superscript refers to the model in the Ramsey outcome. The Ramsey problem is:

$$
\begin{gathered}
\max _{a, k} W(a, k) \equiv \int_{0}^{k}[w(a)-c(x)] d x \\
\text { subject to } \Pi(a, k) \geq 0 \Leftrightarrow \int_{0}^{k}[r(a)-c(x)] d x \geq 0 .
\end{gathered}
$$


In the first-best, $\Pi^{F B}<0$, thus $\Pi(a, k) \geq 0$ must be a binding constraint, i.e., $r(a) k-$ $C(k)=0 \Leftrightarrow a(k)=r^{-1}\left(\frac{C(k)}{k}\right)$. The Ramsey problem can be re-written as:

$$
\begin{aligned}
& \max _{k} W(k) \equiv w\left(r^{-1}\left(\frac{C(k)}{k}\right)\right) k-C(k) \\
& \text { FOC }: \frac{d W}{d k}=0 \Leftrightarrow \underbrace{w^{\prime}(a)}_{<0} \underbrace{a^{\prime}(k)}_{>0} \underbrace{k}_{>0}+\underbrace{w(a)-c(k)=0}_{\text {FOC in the FB }} \text {, thus } k^{R}<k^{F B} .
\end{aligned}
$$

Hence, in the Ramsey solution:

$$
\left\{\begin{array}{c}
a^{R}=r^{-1}\left(\frac{C\left(k^{R}\right)}{k^{R}}\right)>a^{F B} \\
k^{R}<k^{F B} \\
\Pi^{R}=0>\Pi^{F B} \\
W^{R}=\int_{0}^{k^{R}}\left[w\left(a^{R}\right)-c(x)\right] d x<W^{F B}
\end{array} .\right.
$$

The Ramsey solution suggests that to allow the incumbent to recover the NGA coverage cost it is necessary to set retail prices above the marginal cost (zero). This results in inefficient consumption of NGA services and reduced social welfare compared with the first-best.

\subsection{Free market: Monopoly Outcome}

In this section, I compute the free market equilibrium to identify potential market failures (inefficiencies) in the pricing and coverage of NGA services and assess whether there is scope for regulatory intervention to improve social welfare. I use backward induction to solve the model for the subgame perfect Nash equilibrium. First, I solve the incumbent's problem to derive the profit maximizing retail and access prices (in a free market without regulatory intervention, the incumbent can also set the access price to its infrastructure). Second, I solve the incumbent's coverage problem.

Stage III: Retail Price Competition and Access Pricing

Firms in the competitive fringe set prices equal to the access price $a$. The incumbent's problem is:

$$
\begin{array}{r}
\max _{a} \Pi(a) \equiv \int_{0}^{k}[r(a)-c(x)] d x . \\
F O C: \frac{d \Pi}{d a}=0 \Leftrightarrow r^{\prime}(a) k=0 \Leftrightarrow a^{m o n}=\left(r^{\prime}\right)^{-1}(0) .
\end{array}
$$

Stage II: Coverage

The incumbent's problem regarding coverage is:

$$
\begin{array}{r}
\max _{k} \Pi(k)=\int_{0}^{k}\left[r\left(a^{\text {mon }}\right)-c(x)\right] d x . \\
F O C: \frac{d \Pi}{d k}=0 \Leftrightarrow r\left(a^{m o n}\right)-c(k)=0 \Leftrightarrow k^{m o n}=c^{-1}\left(r\left(a^{m o n}\right)\right) .
\end{array}
$$

Hence, the free market (monopoly) equilibrium is:

$$
\left\{\begin{array}{l}
a^{\text {mon }}=\left(r^{\prime}\right)^{-1}(0) \geq a^{R} \\
k^{\text {mon }}=c^{-1}\left(r\left(a^{\text {mon }}\right)\right) \\
\Pi^{\text {mon }}=\int_{0}^{k^{\text {mon }}}\left[r\left(a^{\text {mon }}\right)-c(x)\right] d x>\Pi^{R} \\
W^{\text {mon }}=\int_{0}^{k^{m o n}}\left[w\left(a^{\text {mon }}\right)-c(x)\right] d x<W^{R}
\end{array} .\right.
$$


I can now compare the free market solution to the Ramsey outcome. In the free market equilibrium, the incumbent maximizes profit by setting higher retail (and access) prices. This results in inefficient levels of NGA consumption, as well as lower social welfare. It can be shown that $k^{m o n}<k^{F B}$; however, it is unclear whether $k^{m o n}$ is higher or lower than $k^{R}$.

Retail price inefficiency derives from the incumbent's market power to set access prices to the only available NGA infrastructure. Under-investment in NGA (compared with the first-best) is because the incumbent is unable to capture the full social benefit of coverage. A fraction of that benefit is captured by consumers because there might exist heterogeneity in willingness to pay for the NGA service and firms are unable to price discriminate sufficiently to extract the consumers' full benefit. Hence, regulatory intervention may be desirable from the social perspective to promote price and investment efficiencies.

\section{Fixed Access Price}

In this section, I solve the model for the subgame perfect Nash equilibrium under a fixed access price rule and compare it to the free market (monopoly) outcome. Hereafter, a variable with $*$ in superscript refers to the model with a fixed access price.

Stage III: Retail Price Competition

All firms set retail prices equal to the regulated access price $a$.

Stage II: Coverage

The incumbent's coverage problem is:

$$
\begin{array}{r}
\max _{k} \Pi(k)=\int_{0}^{k}[r(a)-c(x)] d x \\
\text { FOC }: r(a)-c(k)=0 \Leftrightarrow k^{*}=c^{-1}(r(a)) .
\end{array}
$$

The FOC in (2) means that the incumbent will roll-out NGA coverage up to the area where the revenue from that area is equal to the respective coverage cost.

Stage I: Regulatory Regime

The regulator's problem is:

$$
\begin{array}{r}
\max _{a} W(a) \equiv \int_{0}^{c^{-1}(r(a))}[w(a)-c(x)] d x \\
F O C: \frac{d W}{d a}=0 \Leftrightarrow c^{-1}(r(a)) w^{\prime}(a)+(w(a)-r(a)) \frac{d c^{-1}(r(a))}{d r(a)} r^{\prime}(a)=0 .
\end{array}
$$

The fixed access price outcome compares to the free market (monopoly) equilibrium as follows:

$$
\left\{\begin{array}{l}
a^{*}<a^{m o n} \\
k^{*}(a)<k^{m o n} \\
\Pi^{*}<\Pi^{m o n} \\
W^{*} \geq W^{m o n}
\end{array} .\right.
$$

By setting a fixed access price below the monopoly level, the regulator can induce lower retail prices. However, this results in less NGA coverage given that the revenue collected by the incumbent is now limited by the price control. The regulator can set the fixed access price control such that the gains in price efficiency outweigh the welfare losses due to reduction in NGA coverage. In other words, welfare gains for consumers in NGA areas benefiting from lower retail prices will more than compensate the welfare losses for consumers 
that lose NGA access as a result of the fixed access price implementation. The regulator is maximizing social welfare, thus $W^{*} \geq W^{\text {mon }}$ by definition.

\section{Access Price Indexation}

In this section, I analyze an access price rule as a twice differentiable function of NGA coverage, $a=a(k)$. I solve the game set out in Table 1 above under the access price indexation. The indexation rule means that the access price, $a$, uniform across all geographic areas, is only set when the incumbent chooses the total area to cover with NGA, $k$, in stage II of the model. I show that the access price indexation can (i) without increasing access prices, increase coverage and social welfare relative to fixed access pricing; (ii) implement approximately the Ramsey solution; and (iii) under some conditions, implement the firstbest level of NGA coverage with the lowest possible access price. The latter case may be particularly relevant when the regulator's goal is to achieve universal coverage. Hereafter, a variable with $* *$ in superscript refers to the model under access price indexation.

Stage III: Retail Price Competition

This is identical to stage III under a fixed access price as solved above. All firms set retail prices equal to the regulated access price $a$, set as a function of $k$ by the regulator.

Stage II: Coverage

The incumbent's coverage problem is:

$$
\max _{k} \Pi(k)=\int_{0}^{k}[r(a)-c(x)] d x, \text { where } a=a(k)
$$

and the optimal coverage is defined by:

$$
\begin{aligned}
& \text { FOC }: \frac{d \Pi}{d k}=\underbrace{\frac{\partial \Pi}{\partial k}}_{\text {"direct effect" "indexation effect" }}+\underbrace{\frac{\partial \Pi}{\partial a} \frac{d a}{d k}}_{>0 \text { for } a^{\prime}(k)>0 \text { and } a \in\left[0, a^{\text {mon }}\right)}=0 \\
& \Leftrightarrow r(a)-c(k)+\underbrace{r^{\prime}(a) a^{\prime}(k) k}=0 .
\end{aligned}
$$

The "direct effect" accounts for the marginal private benefit and marginal cost of covering an area with NGA assuming that the access price is held constant. The "indexation effect" accounts for the incumbent's profit variation due to changes in the access price via investment in NGA coverage.

Under a fixed access price, the indexation effect is zero because $a^{\prime}(k)=0$. Under the access price indexation, the "indexation effect" is positive because $\partial \Pi / \partial a>0$ for $0 \leq a<a^{m o n}$, and $a^{\prime}(k)>0$ (verified in the proof of Proposition 1) given the purpose of the indexation to reward the regulated firm for extending its coverage. In plain English, the indexation effect results from the fact that the incumbent's profit increases with the access price (if below the monopoly level), while the access price increases with the incumbent's NGA coverage. From an investor's perspective, for a same access price, $a$, the marginal benefit of NGA coverage is higher with access price indexation than with a fixed access price. Proposition 1 below summarizes the benefits of the access price indexation compared with a fixed access price. 
Proposition 1 (Access price indexation vs fixed access price) An access price rule as a function of NGA coverage, $a=a(k)$, can, without increasing the access price, simultaneously (i) expand geographical coverage of NGA, and (ii) enhance social welfare, compared with a fixed access price $a^{*}>0$.

The introduction of an access price as a function of NGA coverage creates a scheme of rewards to the NGA investor. In particular, by investing in further NGA coverage, the firm can charge a higher access price. As a result of the additional incentives to NGA investment generated by the indexation, for a same equilibrium access price, the incumbent invests more with indexation than under a fixed access price. The access price as a function of geographic coverage may be consistent with the "ladder of investment" insofar as access prices are expected to increase over time as the geographic coverage of the innovative service expands (Avenali et al. 2010). This signals to access seekers, particularly new entrants without a critical mass of customers, that their business models should not rely on the unlimited availability of low-cost access services and that some form of facility-based competition is expected to take place in the future.

In relation to social welfare, under a fixed access price, in equilibrium, the marginal social net benefit from investment is positive implying that further NGA coverage would enhance social welfare. The social welfare variation due to the implementation of the access price indexation must be positive as it entails further coverage, when compared with a fixed access price policy. If $a=a^{* *}=a^{*}$, the increase in social welfare is explained by the expansion of NGA coverage to the extent that the coverage cost of an additional NGA area is lower than the gross social welfare generated.

Stage I: Regulatory Regime

The regulator's problem is:

$$
\max _{a(k)} W(a) \equiv \int_{0}^{k}[w(a)-c(x)] d x
$$

subject to $\Pi(k) \geq 0$ (incumbent's participation constraint)

$$
\begin{array}{r}
d \Pi(k) / d k=0 \text { (incumbent's FOC) } \\
d^{2} \Pi(k) / d k^{2}<0 \text { (incumbent's SOC) } \\
a(k) \in\left[0 ; a^{m o n}\right] \text { and twice differentiable. }
\end{array}
$$

From the incumbent's profit function, the access price can be written as follows:

$$
\Pi(k)=\int_{0}^{k}[a(k) q(a(k))-c(x)] d x \Leftrightarrow a(k)=\frac{C(k)}{q(a(k)) k}+\frac{\Pi(k)}{q(a(k)) k} .
$$

Note that if $\Pi(k)=0$ for any $k, a(k)$ corresponds to the average total cost per NGA consumer across all covered areas, which is the minimum the incumbent must be provided with to cover $k$ areas with NGA. The regulator can set the functional form for $a(k)$ such that it shapes $\Pi(k)$ to induce the incumbent to choose a given $k^{G} \in\left[0 ; k^{\max }\right)$, where $k^{\max }$ is the maximum coverage that can be achieved subject to the incumbent being able to recover the total cost. In particular, the regulator can set a functional form for $a(k)$ such that $\Pi(k) \geq 0$ is concave in $k$ and with maximum at $k=k^{G}$, i.e., $k^{G}$ satisfies simultaneously the FOC 
and the SOC of the incumbent's coverage problem. A possible solution for the regulator's problem in (4) is, for example:

$$
a(k)=\frac{C(k)}{q(a(k)) k}+\frac{\varepsilon k\left(2 k^{G}-k\right)}{q(a(k)) k},
$$

where $k^{G}$ and $\varepsilon$ are both set by the regulator. Note that the access price function in (5) can also be rewritten as $a(k)=r^{-1}\left(\frac{C(k)+\Pi(k)}{k}\right)$ and its existence follows from the assumptions on $r(a)$. In the example above, $\Pi(k)=\varepsilon k\left(2 k^{G}-k\right)$. Thus, the FOC with respect to $k$ for the incumbent becomes $\varepsilon\left(2\left(k^{G}-k\right)\right)=0 \Leftrightarrow k=k^{G}$, while the SOC, $-2 \varepsilon<0$, is satisfied for any $\varepsilon>0$ which can be set arbitrarily small. Proposition 2 below covers the feasibility of an approximation to the Ramsey outcome and the first-best coverage level under the access price indexation.

Proposition 2 (Ramsey outcome and first-best coverage) An access price rule as a function of NGA coverage, $a=a(k)$, can implement ( $i)$ approximately the Ramsey outcome; or (ii) the first-best coverage level, if the monopoly revenue is above the total coverage cost, $C\left(k^{F B}\right)$.

Let the access price indexation be defined by (5). The regulator's problem becomes:

$$
\begin{array}{r}
\max _{k^{G}, \varepsilon} W(a, k) \equiv \int_{0}^{k}[w(a)-c(x)] d x \\
\text { subject to } a(k)=\frac{C(k)}{q(a(k)) k}+\frac{\Pi(k)}{q(a(k)) k} ; a(k) \in\left[0 ; a^{\text {mon }}\right] \\
\Pi(k)=\varepsilon k\left(2 k^{G}-k\right) \geq 0 \text { (incumbent's participation constraint) } \\
k=k^{G} \text { (incumbent's FOC) } \\
-2 \varepsilon<0 \text { (incumbent's SOC). }
\end{array}
$$

The regulator can set $k^{G}=k^{R}$ and $\varepsilon>0$ arbitrarily small, such that $a(k)=$ $\frac{C(k)}{q(a(k)) k}+\frac{\varepsilon k\left(2 k^{R}-k\right)}{q(a(k)) k}$. If so, $\lim _{\varepsilon \rightarrow 0} a\left(k^{R}\right)=a^{R}$, while the incumbent's profit converges to zero. Hence, as $\varepsilon \rightarrow 0$, the Ramsey solution can be approximately implemented with access price indexation.

Stage I Revisited: First-Best Coverage Level

Suppose now that the regulator's objective is to achieve the first-best coverage level, rather than maximizing total social welfare, i.e., it sets: $k^{G}=k^{F B}$. However, such coverage is only feasible if the monopoly revenue is sufficiently high to cover the respective coverage cost, i.e., $\int_{0}^{k^{F B}}\left[r\left(a^{m o n}\right)-c(x)\right] d x>0$. In general, the first-best coverage is defined by:

$$
w\left(a^{F B}\right)-c(k)=0 \Leftrightarrow w\left(a^{F B}\right)=c(k)
$$

while the maximum feasible level of coverage is defined by:

$$
r\left(a^{m o n}\right) k-C(k)=0 \Leftrightarrow r\left(a^{m o n}\right)=\frac{C(k)}{k} .
$$

Note that $w\left(a^{F B}\right) \geq r\left(a^{m o n}\right)$ given that the left-hand side of the inequality accounts for the full value generated by coverage in an area in the first-best, while the right-hand side accounts only for the revenue captured by the monopolist in that same area. Also, $c(k)>$ $C(k) / k$ given that the deployment cost is convex by assumption. In general, the solutions 
of (7) and (8) with respect to $k$ do not coincide, and the maximum feasible level of coverage may be above or below the first-best coverage. For example, assume that $C(k)=k^{2} / 2$, and given that the monopolist revenue is a fraction $\lambda \in[0,1]$ of the total welfare, then $r\left(a^{m o n}\right)=\lambda w\left(a^{F B}\right)$. In this example, the first-best coverage is $k^{F B}=w\left(a^{F B}\right)$, while the maximum feasible level of coverage is $k^{\max }=2 \lambda w\left(a^{F B}\right)$. Hence, if $\lambda \in[0,0.5)$, the first-best coverage is unfeasible, while if $\lambda \in[0.5,1]$ the first-best coverage is feasible.

\section{Discussion}

In this section, I discuss further the features of access price indexation and the robustness of the results set out above with regard to observability and verifiability, and uncertainty and asymmetric information.

\subsection{Observability and Verifiability}

The assumption that geographical coverage of fiber broadband is observable and verifiable to a third party is fundamental for access price indexation to fulfil its intended outcomes. In this section, I discuss the reasonableness of that assumption, bearing in mind that firms may attempt to exploit the access price indexation to increase their own profits. To gain a competitive advantage at the downstream level and, ultimately, increase profits, a regulated firm may have an incentive to report a wider coverage area than it owns.

Regulators may at least partially observe and verify at some cost the coverage of fiber optic infrastructures. The economics of fiber deployment is usually characterized by high fixed costs of which the dominant component is the civil works: digging the roads including obtaining construction permits and laying ducts (poles and direct buried cables can be used in some areas as well) whose existence is observable and verifiable. Moreover, regulators engage with stakeholders in the sector. Therefore, if a regulated firm reports a fiber coverage that it does not own, eventually an access seeker will become aware of that fact and expose such misconduct. ${ }^{6}$ Also, the quality of fiber networks may be inferred from fault rate information, consumer complaints, and a number of websites that allow testing of broadband speeds. Some regulators also produce maps showing accurate information on broadband take-up, speeds, and availability.

A further option to tackle potential unintended consequences of indexation is to attach a price floor and a price cap to the access price indexation rule. For example, the regulator may set a price cap equal to the expected optimal fixed access price and a price floor close to the expected access price under the indexation approach. This guarantees that in the event of a mistaken calibration of the indexation rule or a coverage misreport by the regulated firm, the access price will still be within a reasonable range, which mitigates uncertainty to the industry.

\footnotetext{
${ }^{6}$ For example, when firms request access in an area that is allegedly covered with fiber by the regulated firm while effectively it is not. In this case, given the mechanics of access price indexation, access seekers have an incentive to report such type of misconduct to pay lower access prices. Other ways to obtain relevant information from the regulated firm include obligation to publish regulatory statements on a regular basis, and formal information requests.
} 


\subsection{Uncertainty and Asymmetric Information}

The comparison between a fixed access price and access price indexation was set out on the basis that there is no uncertainty about cost or demand for NGA services, and no asymmetric information between regulator and regulated firm. The analysis suggests that, with low levels of uncertainty and asymmetric information, the access price indexation is a more efficient regulatory approach than fixed access prices, i.e., the regulator can achieve higher welfare levels with the former, rather than the latter.

Uncertainty is as much a problem under the indexation approach as it is under the fixed access price approach. If uncertainty is construed as an increase in the minimum expected return that a firm must be provided with to cover an area with NGA, then it may be modelled as an increment of the cost curve of NGA coverage. In this case, if uncertainty does not alter the properties of $C(k)$ and information is symmetric between regulator and regulated firm, it is straightforward that the results on access price indexation extend to scenarios of uncertainty. ${ }^{7}$ Also, see Bourreau et al. (2018) on how regulatory regimes are affected in the presence of demand uncertainty.

For a regulator, the risks from inadvertently setting price controls either above or below actual cost are usually asymmetric. If the price control is set "too high," there is a sacrifice of static efficiency. If the price is set "too low," the sustainability of the firm is put at risk, and even if the firm is able to continue to operate it might strongly affect investment decisions in the sector in the long run, and ultimately harm social welfare. For example, if the regulator is relatively more averse to set a price "too low," rather than"too high," it might base the price control decisions on a cost curve $C^{+}(k)>C(k)$, for $0 \leq k \leq \bar{K}$, to mitigate that risk. If regulator and firm hold the same information, it is expected that the indexation approach weakly dominates a fixed price since with indexation the regulator can choose to set the same price at all investment levels. However, if the regulator's risk aversion to a "too low" price control is sufficiently high, it may prefer not to set a price control at all.

Regulators are often at an informational disadvantage relative to regulated firms. In light of such asymmetry, a profit maximizing firm may have an incentive to overstate the cost and (or) understate the demand to influence the regulator to set a "softer" price control. This means that if the regulator was to set an indexation rule based on biased information, the firm could face a more favorable menu of options in terms of profit. The regulator may consider combining the indexation approach with other complementary regulatory instruments such as a price cap to mitigate the scope for gaming by the firm. In extreme cases of asymmetric information, e.g., the regulator only holds a forecast of the cost at the national level, and not the cost of deploying NGA in uncovered areas, the indexation approach might prove impractical.

\section{Conclusions}

Investment incentives have been at the core of the access debate. Some authors argue that networks will not invest in facilities subject to strong access regulation, e.g., Sidak and Spulber (1996). Others have supported the idea of forced access because of the gains in static efficiency, but advise that the access price must take into account investment incentives,

\footnotetext{
${ }^{7}$ This is subject to the existence of areas where the uncertainty-adjusted coverage cost is below the monopoly revenue. Otherwise, no NGA coverage would be feasible.
} 
e.g., Laffont and Tirole (2001). This paper contributes to this debate with a suggestion of access price controls as a function of investments in geographic coverage.

I show that having an access price as a function of geographic coverage of a service can extend its coverage without sacrificing retail price efficiency, and ultimately enhance social welfare vis-à-vis a fixed access price. Moreover, in the model, the indexation to coverage may be used to achieve approximately the Ramsey outcome, or the first-best coverage level. This suggests that access price indexation is a potential tool to reduce the need for public subsidies for fiber deployment and the respective tax distortions when compared with a fixed access price.

The results in this paper extend qualitatively to other sets of assumptions, e.g., a regulator that cannot commit to an access price rule, multi-period competition, and differentiated services. Such changes affect as much the indexation as the fixed access price approach preserving the social welfare relativity between the two approaches.

Acknowledgements I thank Steffen Hoernig for extensive comments, suggestions and discussions on matters related to this paper. I also wish to thank Bruno Basalisco, Carlo Cambini, Christiaan Hogendorn, David Sauer, Diogo Lucena, Fabio Manenti, Giovanni Tabacco, Heski Bar-Isaac, Inês Morão, Lawrence White, Luís Cabral, Marc Bourreau, Paula Gonzalez, Pedro Pita Barros, Tiago Pires, the Coordinating Editor Kai Hueschelrath and two anonymous referees for useful comments and suggestions on earlier versions of this paper. This paper extends previous research work I carried out at Nova School of Business and Economics, and at NYU - Stern School of Business with financial support from Fundação para a Ciência e a Tecnologia under the scholarship BD/47421/2008 which is gratefully acknowledged. The analyses, opinions and findings in this paper represent the views of the author, and should not be interpreted as an official position of the institutions of affiliation. All errors are my responsibility.

Open Access This article is licensed under a Creative Commons Attribution 4.0 International License, which permits use, sharing, adaptation, distribution and reproduction in any medium or format, as long as you give appropriate credit to the original author(s) and the source, provide a link to the Creative Commons licence, and indicate if changes were made. The images or other third party material in this article are included in the article's Creative Commons licence, unless indicated otherwise in a credit line to the material. If material is not included in the article's Creative Commons licence and your intended use is not permitted by statutory regulation or exceeds the permitted use, you will need to obtain permission directly from the copyright holder. To view a copy of this licence, visit http://creativecommonshorg/licenses/by/4.0/.

\section{Appendix}

Proof of Proposition 1 (i) Under the fixed access price, from (2) we have that $r(a)=$ $c(k) \Leftrightarrow a=c(k) / q(a)$. The convexity of $C(k)$ implies that $c(k)>C(k) / k$. Thus, $a>C(k) /(q(a) k) \Leftrightarrow a q(a) k-C(k)>0$, i.e., the incumbent's profit is strictly positive under the fixed access price. Under the access price indexation, from (3), we have that $r(a)+r^{\prime}(a) a^{\prime}(k) k=c(k)$, where $r^{\prime}(a)>0$ for $a \in\left[0 ; a^{\text {mon }}\right)$ by assumption, and $a^{\prime}(k)>0$ as will be shown further below. Thus, for a same $a=a^{*}$, the marginal benefit of coverage under indexation, $r(a)+r^{\prime}(a) a^{\prime}(k) k$, is larger than the marginal benefit of coverage under a fixed access price, $r(a)$, resulting in $k^{* *}>k^{*}$. For a same $a=a^{*}$, the incumbent can invest above $k^{*}$ to the extent that the profit is non-negative.

Proof that $a^{\prime}(k)>0$. The incumbent's profit function can be rewritten as $a(k)=$ $r^{-1}\left(\frac{C(k)+\Pi(k)}{k}\right)$. Let $y \equiv \frac{C(k)+\Pi(k)}{k}$. Thus, $a^{\prime}(k)=\left(r^{-1}\right)^{\prime}(y) d y / d k$. The term $\left(r^{-1}\right)^{\prime}(y)>0$ for $y \in\left[0 ; r\left(a^{m o n}\right)\right)$ and $r^{-1} \in\left[0 ; a^{m o n}\right)$, given $r^{\prime}(a)>0$ for 
$a \in\left[0 ; a^{\text {mon }}\right)$. The term $\frac{d y}{d k}=\frac{d\left(\frac{C(k)}{k}\right)}{d k}+\frac{d\left(\frac{\Pi(k)}{k}\right)}{d k}>0$ for $\Pi(k) / k$ sufficiently close to zero. In particular, $\frac{d\left(\frac{C(k)}{k}\right)}{d k}=\frac{c(k) k-C(k)}{k^{2}}>0$ by convexity of $C(k)$; and $\frac{d\left(\frac{\Pi(k)}{k}\right)}{d k}$ close to zero, for example, if the regulator defines $a(k)$ as in (5), then $\frac{d\left(\frac{\Pi(k)}{k}\right)}{d k}=-\varepsilon$, where $\varepsilon$ is a constant defined by the regulator arbitrarily close to zero.

(ii) Comparing the welfare levels under the access price indexation and the fixed access price outcomes: $W^{* *}=\int_{0}^{k^{* *}}\left[w\left(a^{*}\right)-c(x)\right] d x=\int_{0}^{k^{*}}\left[w\left(a^{*}\right)-c(x)\right] d x+$ $\int_{k^{*}}^{k^{*}}\left[w\left(a^{*}\right)-c(x)\right] d x>\int_{0}^{k^{*}}\left[w\left(a^{*}\right)-c(x)\right] d x=W^{*}$, where the inequality is because $\int_{k^{*}}^{k^{* *}}\left[w\left(a^{*}\right)-c(x)\right] d x>0$ given that $r\left(a^{*}\right)=c\left(k^{*}\right)$ from (2), which implies $w\left(a^{*}\right)>$ $c(x)$ for $x \in\left[k^{*}, k^{* *}\right]$ and $k^{* *}$ sufficiently close to $k^{*}$.

Proof of Proposition 2 (i) Let the access price indexation be defined by (5). Consider the regulator's problem set out in (6). If $\varepsilon \rightarrow 0$, the solution of problem (6) converges to the solution of problem (1). This is because both problems share the same differentiable objective function, $W$, and as $\varepsilon \rightarrow 0$, the binding constraint in both problems becomes the same (incumbent's profit converges to zero). The regulator can set $a(k)=\frac{C(k)}{q(a(k)) k}+$ $\frac{\varepsilon k\left(2 k^{R}-k\right)}{q(a(k)) k}$. If so, $\lim _{\varepsilon \rightarrow 0} a\left(k^{R}\right)=a^{R}$. Hence, as $\varepsilon \rightarrow 0$, the Ramsey solution can be approximately implemented with access price indexation.

(ii) Let the access price indexation be defined by (5). The regulator can set $k^{G}=k^{F B}$ and $\varepsilon>0$ arbitrarily small, such that $a(k)=\frac{C(k)}{q(a(k)) k}+\frac{\varepsilon k\left(2 k^{F B}-k\right)}{q(a(k)) k}$. By the incumbent's FOC with respect to $k$, we have that $k=k^{F B}$, while the SOC, $-2 \varepsilon<0$, is satisfied for any $\varepsilon>0$ which can be set arbitrarily small. If $\int_{0}^{k^{F B}}\left[r\left(a^{m o n}\right)-c(x)\right] d x>0$, then $k^{F B}$ can be implemented given that $a(k)$ ensures full cost recovery plus an arbitrarily small profit. If $\int_{0}^{k^{F B}}\left[r\left(a^{m o n}\right)-c(x)\right] d x<0, k^{F B}$ cannot be achieved because the maximum revenue that can be captured by the incumbent, $r\left(a^{m o n}\right) k^{F B}$, is insufficient to cover the cost of covering $k^{F B}$ areas, $C\left(k^{F B}\right)$. Thus, in this case, the participation constraint does not hold. Finally, if $\int_{0}^{k^{F B}}\left[r\left(a^{m o n}\right)-c(x)\right] d x=0$, then the incumbent's profit would be zero, which implies $\varepsilon=0$ and the failure to satisfy the incumbent's SOC.

\section{References}

Avenali A, Matteucci G, Reverberi P (2010) Dynamic access pricing and investment in alternative infrastructures. International Journal of Industrial Organization 28(2):167-175

Bourreau M, Cambini C, Hoernig S (2015) Geographic access markets and investments. Inf. Econ. Policy 31(C):13-21

Bourreau M, Cambini C, Hoernig S (2018) Cooperative investment, access, and uncertainty. International Journal of Industrial Organization 56(1):78-106

Brito D, Pereira P, Vareda J (2010) Can two-part tariffs promote efficient investment on next generation networks? Int J Ind Organ 28(3):323-333

Cambini C, Jiang Y (2009) Broadband investment and regulation: a literature review. Telecommunications Policy 33(10-11):559-74

Cave M (2006) Encouraging infrastructure competition via the ladder of investment. Telecommun Policy 30(3-4):223-37

Cave M, Vogelsang I (2003) How access pricing and entry interact. Telecommun Policy 27(10-11):717-27

Czernich N, Falck O, Kretschmer T, Woessmann L (2011) Broadband Infrastructure and Economic Growth. Econ J 121(552):505-32

European Commission (2016). https://ec.europa.eu/commission/presscorner/detail/en/IP_16_3008 
Faulhaber G, Hogendorn C (2000) The market structure of broadband telecommunications. J Ind Econ 48(3):305-29

Federal Communications Commission (2016). https://apps.fcc.gov/edocs_public/attachmatch/FCC-16-6A1. pdf

Flacher D, Jennequin H (2014) Access regulation and geographic deployment of a new generation infrastructure. Telecommunications Policy 38(8-9):741-59

Foros O, Kind HJ (2003) The broadband access market: competition, uniform pricing and geographical coverage. J Regul Econ 23(3):215-35

Gans J (2001) Regulating private infrastructure investment: optimal pricing for access to essential facilities. Journal of Regulatory Economics 20(2):167-89

Guthrie G (2006) Regulating infrastructure: the impact on risk and investment. Journal of Economic Literature 44(4):925-72

Henriques D (2011) Can access price indexation promote efficient investment in Next Generation Networks? https://papers.ssrn.com/sol3/papers.cfm?abstract_id=1955209

Hoernig S, Vareda J (2010) Racing for investment under mandatory access, The B.E. Journal of Economic Analysis \& Policy 10(1):67

Hori K, Mizuno K (2009) Competition schemes and investment in network infrastructure under uncertainty. Journal of Regulatory Economics 35:179-200

Hurkens S, Jeon D-S (2008) A retail benchmarking approach to efficient two-way access pricing: no termination-based price discrimination. RAND Journal of Economics 39(3):822-49.

Klumpp T, Su X (2010) Open access and dynamic efficiency. American Economic Journal: Microeconomics 2(2):64-96

Laffont J-J, Tirole J (2001) Competition in telecommunications Boston, MA: MIT Press

Lestage R, Flacher D (2009) Le déploiement des réseaux d'accès à très haut débit: régulation et inégalités géographiques. Revue d'économie industrielle 127:15-45

Nitsche R, Wiethaus L (2011) Access regulation and investment in Next Generation Networks - a ranking of regulatory regimes. International Journal of Industrial Organization 29(2):263-72

Sauer D (2012) Access rules and investment incentives. https://sites.google.com/site/davidfsauer/research

Sidak G, Spulber D (1996) Deregulatory takings and breach of the regulatory contract. New York University Law Review 71(4):851-999

Valletti T (2003) The theory of access pricing and its linkage with investment incentives. Telecommunications Policy 27(10-11):659-75

Valletti T, Hoernig S, Barros PP (2002) Universal service and entry: the role of uniform pricing and coverage constraints. Journal of Regulatory Economics 21(2):169-90

Publisher's Note Springer Nature remains neutral with regard to jurisdictional claims in published maps and institutional affiliations. 